\title{
A Utopia de Thomas More: o debate político e a imersão no seu tempo
}

Adriano Saturnino dos Santos

\section{Resumo:}

Este trabalho tem por objetivo último, partindo das implicações humanistas na obra de Thomas Morus, A Utopia, discutir alguns pressupostos políticos e sociais comumente associados ao Humanismo Cívico Florentino, além de comentar as relações entre o movimento italiano e sua apropriação na Inglaterra, configurando uma vertente do chamado Humanismo do Norte. Este estudo procura também verificar como a obra em questão, a despeito de certos artifícios empregados por seu autor, não escapa de uma profunda imbricação com a época de sua produção.

Palavras-chave: Humanismo Cívico Florentino, Humanismo do Norte, Otium e Negotium, Melhor estado de uma Comunidade, Utopia. 


\section{Do Humanismo cívico florentino ao Humanismo do Norte}

Com o despontar do século XV, observa-se a constituição (já com mostras iniciais no século XIV) de um modo de pensamento político e social, conhecido como Humanismo, tendo como principal centro a cidade de Florença. Muito se discute sobre suas origens: por um lado, destaca-se o humanismo como tributário da tradição intelectual medieval, que teria fornecido as bases para o desenvolvimento ulterior da pretensa "nova filosofia". Assim, conforme assinala Kristeller, "os humanistas não inventaram um novo campo de ciência ou uma nova atividade profissional, mas introduziram um estilo novo, classicista, na tradição da retórica medieval". ${ }^{\mathrm{I}}$ Por outro lado, outra interpretação, contrária a essa ideia de continuidade da tradição medieval, afirma o humanismo, assim como todo o movimento Renascentista, como uma mudança súbita e abrupta: Hans Baron situa essa ruptura por volta de I400, quando há uma mudança de tom nos escritos da época, mudança caracterizada pela separação entre o tratamento da sabedoria humana e a transcendência religiosa. Tal discordância a respeito das origens do humanismo seria tema para outra discussão bastante rica e extensa, mas não faz parte do objeto deste estudo. Cumpre assinalar esse quadro para demonstrar o ambiente intelectual das cidades italianas.

Essas ideias, novas ou não tão novas assim, não tardaram a ser difundidas em outras localidades, longe de seu ambiente de origem. A princípio, os humanistas italianos constituíram-se como o grande vetor dessa propagação, a partir da segunda metade do Quattrocento, dirigindo-se a diversas universidades ao norte dos Alpes. Sua atuação privilegiou fortemente o combate ao currículo escolástico e a campanha pelas humanidades. Somou-se a esse esforço de difusão da cultura renascentista o surgimento da imprensa, e o livro impresso configurou-se como a arma mais efetiva nesse processo. Skinner afirma: "nenhum grupo percebeu tão depressa quanto os humanistas as potencialidades do novo meio de comunicação". ${ }^{2}$ Cabe ainda adicionar aos elementos já expostos o número crescente de estudantes das universidades do Norte que seguiram para a Itália com o intuito de aumentar seu conhecimento dos estudos humanistas. Temos, assim, uma ampla circulação das ideias humanistas pelas principais instituições de ensino europeias.

I Paul Kristeller. Tradição clássica e pensamento do Renascimento. Trad. Artur Morão. Lisboa: Edições 70, I995, p. 107 .

2 Quentin Skinner. As fundações do pensamento político moderno. Trad. Laura Teixeira Motta e Renato Janine Ribeiro. São Paulo: Companhia das Letras, I996, p. 2 I5. 
Considerando o ambiente inglês, pano de fundo deste trabalho, a penetração das ideias humanistas encontrou grande favorecimento a partir do momento em que elas se ocuparam dos temas religiosos, envidando esforços na reconciliação do legado clássico com a tradição cristã; exemplo disso é a primeira resenha crítica do Novo Testamento realizada por Lorenzo Valla. Justamente nesse período de orientação ao campo religioso, os intelectuais ingleses estabeleceram os primeiros contatos com a Itália. John Colet, após uma estadia de dois anos na Itália, proferiu palestras sobre as Epístolas de São Paulo, em Oxford. Colet interpretou os ensinamentos de São Paulo e seu trabalho missionário tendo como balizas o cristianismo primitivo e o paganismo.

Nota-se como, inicialmente, o humanismo na Inglaterra esteve vinculado ao contexto universitário. Porém, uma vez estabelecidos os primeiros contatos, o incipiente humanismo inglês pôde extrapolar os muros das universidades, atingindo a vida social e política. Formou-se em Londres, tendo como figuras centrais Colet e Thomas More, um círculo de intelectuais voltados às preocupações sociais e políticas.

É imperativo, entretanto, estabelecer alguns limites nesse processo de assimilação. Não é possível avaliar os progressos do humanismo no Norte da Europa numa relação direta e imediata com a atividade cultural italiana. Os humanistas do Norte apenas se mostraram receptivos às ideias que, de alguma forma, encontravam ressonância em suas experiências, bem diversas das italianas. Por exemplo, duas questões de grande importância na teoria política italiana - a necessidade de se conservar a liberdade política e os perigos para a liberdade que representavam, na península, os exércitos mercenários permanentes - não tiveram a mesma relevância para os humanistas do Norte. Além disso, outros pontos foram conscientemente refutados pelos estudiosos do Norte, caso da justificação da guerra como um expediente político e da "razão de Estado", entendida enquanto possibilidade de utilizar os diversos recursos, mesmo os mais reprováveis, para se alcançar vantagens para a comunidade como um todo. Portanto, mesmo que se considere a teoria política da Renascença do Norte como extensão e consolidação de preceitos já consagrados na Itália do século XV, não se deve perder de vista que isso não significou a mera repetição mecânica e acrítica. ${ }^{3}$

As principais ideias do Humanismo do Norte serão objeto de uma discussão mais pormenorizada na sequência do texto, na análise da obra de Thomas More.

3 Essa discussão encontra-se amplamente exposta em Quentin Skinner. As fundações do pensamento político moderno. Trad. Laura Teixeira Motta e Renato Janine Ribeiro. São Paulo: Companhia das Letras, I996 


\section{A Utopia de Thomas More}

Thomas More deve ser localizado entre a maioria dos humanistas do Norte, na medida em que compartilha de suas premissas teóricas, de seus argumentos e questões. Ao longo da narrativa de A Utopia transparecem, ainda que pelo filtro da ironia, muitas das concepções defendidas pelos demais humanistas do Norte.

Pode-se observar no livro de More uma tentativa de discussão acerca do melhor estado de uma comunidade, colocando a Ilha de Utopia como o exemplo de uma República ideal. Essa discussão não é nova no pensamento político renascentista, visto que foi suscitada por uma série de filósofos políticos escolásticos na esteira da discussão de Aristóteles em "A Política". ${ }^{4} \mathrm{De}$ acordo com os humanistas, uma república estaria em seu melhor estado se duas asserções pudessem ser feitas: uma, era que as leis fossem justas e servissem para promover o bem comum dos cidadãos e a outra, era que os cidadãos fossem, em consequência, capazes de buscar a própria felicidade, da maneira mais adequada à natureza e dignidade do homem. ${ }^{5}$

Mas como garantir essas condições? A partir daí, iniciou-se um grande debate, que envolvia o papel dos homens, mais especificamente dos homens sábios, na vida política. Uma ideia muito cara aos humanistas cívicos da Itália, e que foi incorporada pelo Humanismo do Norte, era a noção de que o papel dos teóricos da política na vida do Estado relacionava-se ao Conselho de Estado; conforme nos diz Skinner, "tenderam a considerar-se, acima de tudo, conselheiros políticos - como autores de manuais e provedores de conselhos dos mais sábios a reis, príncipes e magistrados". ${ }^{6}$ Assim, esses intelectuais lançaram-se à carreira de secretário, conselheiro ou embaixador. Associada a essa questão do serviço público, surgia o clássico debate humanista sobre as vantagens e desvantagens do otium e negotium, da vida contemplativa e da vida ativa. Inicialmente, defendia-se que o único meio para a obtenção de uma república em seu melhor estado era atribuir todos os negócios públicos a um guardião

\footnotetext{
4 Essa reflexão baseia-se na discussão realizada por Quentin Skinner. "Sir Thomas More's Utopia and the language of Renaissance humanism”. In: PAGDEN, Anthony (org.) - The Languages of political theory in early-modern Europe. Cambridge [Cambridgeshire]; New York : Cambridge University Press, Série Ideas in Context, I987.

5 Tal assertiva está amplamente balizada pelas concepções de Aristóteles, que relacionava a natureza de uma coisa como seu estágio final. Aristóteles. A Política. Trad. Roberto Leal Ferreira. São Paulo: Martins Fontes, I998.

6 Quentin Skinner. As fundações do pensamento político moderno. Trad. Laura Teixeira Motta e Renato Janine Ribeiro. São Paulo: Companhia das Letras, I996, p. 235.
} 
sensato e deixar todos os demais cidadãos livres para buscar a própria felicidade; assim, dentro de uma concepção platônica, o filósofo deveria manter distância da vida ativa, dedicando-se à contemplação e aos estudos. Tal era a posição dos mais antigos humanistas, incluindo o próprio Petrarca. Acreditava-se que a alternativa, a vida de negotium, vivida pelos cortesãos, funcionários públicos e conselheiros dos príncipes, era suscetível à corrupção, uma vida cheia de hipocrisia e mentiras.

Contudo, opôs-se a essa postura outra corrente que sustentava, por contraste, uma ativa cidadania no interior de um sistema republicano inteiramente participativo. Essa premissa conferiu ao Humanismo Italiano, mormente o do Quattrocento florentino, o seu caráter "cívico". Antes, a vida contemplativa assentava-se na convicção de que a verdadeira sabedoria exigia a libertação em relação às paixões. Agora, "a nova ênfase nas virtudes da vida ativa não somente constituiu um laço com o patriotismo vigoroso das comunas italianas, mas também se achava unida a uma nova psicologia: a observação e a aceitação crescentes das forças emocionais na natureza humana",7 Com essa nova interpretação da vida ativa, o afastamento em relação aos negócios públicos era visto como uma atitude incorreta e irresponsável, que redundaria em danos à República. Essa escolha da ocupação pública era explicada pela tese de que todo conhecimento deve ter algum uso, e pela ideia de que, assim procedendo, os homens cultos estariam cumprindo um serviço público de grande importância, favorecendo a ordem da República e ajudando a preservar a melhor forma de governo.

Deve-se ressaltar que essa nova escala de valores não era uma invenção da Renascença, mas o fruto de uma apropriação das ideias e do vocabulário dos últimos grandes defensores da república romana, principalmente Gícero. Em sua obra, De officiis, aponta como princípio crucial que todo o elogio da virtude deriva da ação. Mesmo Aristóteles manifesta preferência pela vida ativa; defendendo a escolha pela vida virtuosa, ele vê pontos defensáveis nos dois modelos de vida, ativa e contemplativa, mas termina afirmando que "a felicidade consiste na ação" e que "a melhor vida, tanto para o Estado inteiro como para cada um em particular, é, sem dúvida, a vida ativa". ${ }^{8}$

É no interior desse debate que More insere uma parte muito importante de sua obra. A necessidade do envolvimento ativo dos homens cultos na vida política dos Estados transparece de modo dúbio: Rafael Hitlodeu, o narrador das grandes novidades sobre o novo mundo, tece reflexões sobre as diferentes

7 Hans Baron. En busca del humanismo cívico florentino. Ensayos sobre el cambio del pensamiento medieval al moderno. Trad. Miguel Abelardo Camacho Ocampo. México: Fondo de Cultura Econômica, I993, p. 300. 8 Aristóteles. A Política. Trad. Roberto Leal Ferreira. São Paulo: Martins Fontes, I998, p. 63. 
formas de governo, suas virtudes e defeitos, e em vista de tanta erudição, seus interlocutores, o próprio Thomas More e seu amigo Pedro Gil, instam o viajante a servir à causa pública, servindo de conselheiro ao governante; contudo, Hitlodeu, numa postura visivelmente platônica, recusa-se a tal atividade: "Presentemente sou livre, vivo como quero, e duvido que muitos dos que vestem a púrpura possam dizer o mesmo. Muita gente ambiciona os favores do trono; os reis não sentirão falta, se eu e dois ou três da minha têmpera não nos encontrarmos entre os cortesãos". ${ }^{9}$ Apesar da insistência de seus interlocutores, Hitlodeu mantém sua posição contrária ao serviço de conselheiro, preferindo a vida contemplativa. Como então compreender essa conclusão que de certa forma vai de encontro aos preceitos humanistas? Quentin Skinner oferece uma resposta interessante, ao afirmar que se trataria de uma dupla ironia de More: se de início ele satiriza o ideal de vida ativa, por fim ele acaba endossando-a, na medida em que Hitlodeu, que no livro I recusava-se a servir de conselheiro, oferece um conselho político no livro II, quando expõe o modo de vida utopiano, descrevendo-o como admirável e digno de imitação; a outra ironia volta-se contra o próprio modo de vida de More, que, no mesmo instante em que escrevia e lançava o livro inicial, entrava para o serviço público. Além disso, pode-se enxergar nessa dupla posição de More sua crença no valor do serviço público aliado, porém, à observação de seus limites e deficiências.

Também é possível ver na obra de Thomas More um exemplar específico do gênero dos "espelhos do príncipe". Os humanistas do Norte fizeram amplo uso desse gênero, no qual a principal motivação era redigir tratados que guiassem os governantes no sentido de uma formação virtuosa e que redundasse, por sua vez, num governo virtuoso. Ampliando essa orientação, vários humanistas escreveram livros de aconselhamento dirigidos não apenas aos príncipes, mas também aos cortesãos, nobres, conselheiros e magistrados, ou ainda, obras de fundo moral que tinham por alvo toda a população. A Utopia, portanto, ao oferecer um exemplo de constituição virtuosa e de instituições dignas de imitação, propõe-se, ainda que de modo velado, como um tratado destinado aos dirigentes, visando o aperfeiçoamento de sua administração.

Outra grande bandeira humanista empunhada por More é a necessidade de combater as injustiças que grassam na sociedade. Ao relatar o ambiente dos conselhos, considerados locais de bajulação, interesse, vaidade e inveja, Hitlodeu narra o episódio em que falou sobre a injustiça da aplicação da pena de morte para os ladrões, pena considerada muito exagerada para o delito e que acabaria por estimular delitos mais graves. À guisa de sugestão, o narrador evoca uma pena

9 Thomas More. A Utopia. São Paulo: Abril Cultural, Coleção Os Pensadores, volume IO, I972, p. I69. 
de trabalhos forçados, tomando o exemplo de um povo desconhecido. Outra injustiça apontada por Hitlodeu é a busca pela satisfação de interesses próprios, desfavorecendo o bem comum. A esse respeito, ele cita como os principais responsáveis pelo estado de miséria do reino (no caso, a Inglaterra) dois grupos sociais: uma nobreza ociosa e exploradora, que contribui para aumentar o desemprego e a miséria (na medida em que os nobres morrem e seus seguidores são despedidos), e uma camada de proprietários de terras (muitas vezes parte da nobreza), que por sua avareza e ambição, extinguem as culturas agrícolas para dar lugar a pastagens para alimentar criações (notadamente de carneiros), tendo como consequências a expulsão de multidões de camponeses, o êxodo rural, o aumento da pobreza e a criminalidade. Destarte, apresenta-se o que era reconhecida como a característica mais corrupta e corruptora da época: a falta de preocupação com o bem comum. A saída para todos esses problemas encontra-se, portanto, na difusão das virtudes na vida política, como mecanismo de promoção da harmonia social: "para eliminar o faccionismo, vencer as corrupções e instituir uma República bem ordenada, a chave está em efetuar o triunfo das virtudes". ${ }^{\text {IO }}$

Dessa forma, como conselheiros, os homens cultos deveriam atuar contra os males que acometiam a sociedade, estimulando o desenvolvimento das virtudes, visto como a chave para o êxito político, e o meio para se adquirir as tais virtudes era por intermédio de uma educação fundamentada nos estudos humanísticos. Pretendia-se, assim, não tanto uma reforma das instituições, mas uma mudança de coração. A prática das virtudes era aconselhada para os dirigentes da classe dominante e, de acordo com os humanistas mais radicais, para toda a população, como condição para uma República ordenada. A busca da virtude se justificaria como um ato cristão: abraçando as virtudes, o príncipe e o povo estariam no caminho para a constituição de um modo de vida cristão, o que contribuiria para o fundamento de uma perfeita República. Os que defendiam tal proposta foram logo denominados humanistas cristãos, e entre eles estavam Erasmo, John Colet e More. Definia-se como verdadeiro cristão aquele que sabia utilizar a razão dada por Deus, a fim de distinguir o bem do mal, e que se esforçava ao máximo para evitar o mal e praticar o bem. Segundo Erasmo, para ser um bom cristão não era necessário ser batizado ou frequentar a Igreja, mas abraçar Cristo em seu coração. Tendo isso em mente, uma das questões mais controversas na obra de More era o fato de ele ter acentuado as grandes qualidades dos habitantes de Utopia ao mesmo tempo em que destacava o fato de não conhecerem o cristianismo. More elogia o fato de os utopianos terem criado uma sociedade virtuosa e nisso consiste a verdadeira santidade. Bem mais

Io Quentin Skinner. As fundações do pensamento político moderno. Trad. Laura Teixeira Motta e Renato Janine Ribeiro. São Paulo: Companhia das Letras, I996, p. 254. 
que os europeus cristãos de nome, os habitantes pagãos de Utopia conseguiram constituir uma república virtuosa, portanto verdadeiramente cristã.

Todas essas ideias encontram-se no livro I d'A utopia. A partir do livro II, Hitlodeu passa a relatar tudo o que viu na Ilha de Utopia, seu povo, sua geografia, suas instituições, sua organização política etc. Perpassa toda a narrativa uma espécie de elogio à organização e racionalização das instituições utopianas, criadas para garantir a harmonia e a ordem (dois ideais humanistas). Num tipo de crítica à nobreza, o livro II nos apresenta o desprezo dos utopianos pelas honrarias dadas a essa classe, pela caça (uma prática reconhecidamente nobre), pelas riquezas etc. Numa oposição ao sistema político europeu, em Utopia muitas das instâncias decisivas cabe ao sufrágio secreto (só não fica muito claro se se trata de sufrágio universal). O trabalho agrícola é de responsabilidade de todos, observando-se um modelo de revezamento de trabalhadores no campo, aliado a um ofício específico que cada habitante adotará; a par do trabalho manual, todos os habitantes têm a oportunidade de se exercitar no campo intelectual, por meio de estudos regulares e cursos públicos. A jornada de trabalho é racionalmente dividida de forma a alternar as horas de trabalho, as refeições e os momentos de descanso e cultivo intelectual.

No tocante à religião, afirma-se no livro II que Utopia não conhecia o cristianismo, mas uma variedade de crenças. O curioso é que não havia, segundo Hitlodeu, um choque entre as diversas tendências: era proibido prejudicar uma pessoa por sua religião. Estava em vigor a liberdade de religião e era totalmente condenada a imposição pela violência e a destruição da religião contrária. Os utopianos acreditavam que a rivalidade religiosa contribuía para a divisão interna, o que ia de encontro com os ideais de unidade e harmonia. Curiosamente, a despeito dessa afirmação da tolerância religiosa, More não reconheceu a Reforma protestante; chegou, inclusive, a defender a erradicação das heresias, como medida necessária para preservar a paz e a segurança do Estado. Geralmente justifica-se tal conduta pelo fato de ter escrito A Utopia sob influência do espírito erasmiano.

Se em Utopia a liberdade de consciência era defendida, reprovava-se, entretanto, a ausência de qualquer crença: a quase totalidade dos utopianos acreditava numa vida futura, e desprezava os indivíduos que só acreditassem na matéria; destarte, não se tolerava o ateísmo. Há que se fazer uma ressalva: se a comunidade de Utopia era tão perfeita e representava o modelo ideal de sociedade e organização, por que esperar por uma nova existência, por que acreditar "numa vida futura, onde castigos são preparados para os crimes e recompensas para as virtudes?"II Parece um contrassenso uma esperança em algo melhor.

II Thomas More. A Utopia. São Paulo: Abril Gultural, Goleção Os Pensadores, volume IO, I972, p. 296. 
Até aqui, vê-se como Thomas More, de certa forma, mantém-se fiel a alguns dos preceitos humanistas. Entretanto, como já foi salientado, o Humanismo do Norte não foi apenas uma cópia do Humanismo cívico italiano, e os humanistas do Norte (More entre eles), buscaram realizar uma crítica dos temas humanistas precedentes. Conforme já foi mencionado, os humanistas do Norte destoam dos humanistas cívicos no que concerne à guerra: para estes, ela era aceitável como um mecanismo político auxiliar, e a força e a violência eram tidas como inerentes ao ofício do homem de Estado. Em Thomas More, a guerra ganha um forte opositor; na descrição da Ilha da Utopia, Hitlodeu informa que os utopianos praticavam sim a guerra, inclusive com a participação de mulheres, mas se tratava ou de uma guerra defensiva, ou de uma guerra para auxiliar seus adversários, ou de uma guerra para libertar um povo oprimido da escravidão e do jugo de um tirano, tendo como meta última o "bem da humanidade". Entretanto, os utopianos não sentem orgulho em vencer uma guerra por meio da força bruta, "(...) nada existe de tão vergonhoso na Utopia como procurar a glória nos campos de batalha", ${ }^{12}$ mas veem muito maior proveito em vencer uma disputa por meio da habilidade e do engenho. Ademais, o governo de Utopia fazia o máximo para evitar mandar seus compatriotas para os combates, preferindo contratar mercenários. Isso sem dúvida contrariava os humanistas cívicos, que não viam com bons olhos, e até censuravam, a contratação de tropas pagas.

\section{Thomas More, um intelectual do século XVI}

Até aqui, temos situado Thomas More como um dos representantes do humanismo do Norte, inclusive em sua crítica ao humanismo cívico. Mas Skinner levanta uma questão que põe em evidência, segundo ele, a grande originalidade de More. Para além de uma contribuição ao programa humanista, A Utopia consiste na maior contribuição da Renascença do Norte à teoria política e na maior das críticas ao Humanismo, escrito por um humanista. Essa crítica tem como ponto de partida o ponto mais controverso do livro de More: a descrição e o elogio, por parte de Hitlodeu, de um modo de vida comunal, de uma sociedade sem hierarquias e sem sinal de troca mercantil com mediação monetária. De fato, segundo a narração de Rafael Hitlodeu, em Utopia os bens são repartidos por todas as classes, os méritos são recompensados e a riqueza nacional é igualmente distribuída. De acordo com Hitlodeu, é impossível a justiça e a prosperidade social num lugar em que a propriedade é um direito individual, onde todas as coisas se medem pelo dinheiro; a liberdade não pode florescer onde a igualdade

I2 Idem, ib. p. 279 . 
não sobrevive. Por isso, em Utopia o dinheiro não tem valor algum, a não ser no trato com outros países, e as pedras e metais preciosos são desprezados como objetos de escravos e crianças. Destarte, Hitlodeu critica uma sociedade injusta e exploradora, cujas injustiça e exploração se assentam sobre as leis. More, de acordo com Skinner, afirma o lugar-comum de que a virtude constitui a única forma de nobreza; entretanto More conclui que em seu tempo a nobreza se mede pela riqueza e posição social. Sua crítica se dirige unicamente àqueles que se consideram superiores por seus bens e posição, e dessa forma se opõe a eles afirmando a virtude como depositária da nobreza. Esse ataque à aristocracia hereditária reflete o questionamento de More à filosofia social de seus amigos humanistas: a maior parte destes afirmava que a virtude deve ser considerada a verdadeira nobreza; entretanto, defendiam que as virtudes normalmente apareciam entre os membros da classe dominante, ressalva que enfraquecia uma tese que, a princípio, era radical. Afirmavam, assim, a compatibilidade entre uma república virtuosa e a existência de hierarquias, precedência e posições. Opondo-se a essa assertiva, More reiterava que para a instituição de uma república virtuosa fazia-se necessária a supressão da estrutura social hierarquizada. Assim, More afirma que os utopianos, ao colocarem em prática esse princípio igualitário, puderam instituir uma forma de governo virtuosa.

More apresenta como causa da hierarquização a desigual distribuição do dinheiro e da propriedade privada, o que permite que poucos possam exercer seu domínio sobre muitos. Tendo isso em vista, a solução seria a abolição do dinheiro e da propriedade privada. Ao propor isso, More estaria, segundo Skinner, levando as conclusões humanistas já explicitadas a novos patamares teóricos, o que significaria um avanço. Skinner nos diz que "(...) More na verdade acusa os humanistas seus contemporâneos de não conseguir identificar as consequências dos argumentos que eles próprios haviam formulado (...) estava se tornando um lugar-comum apontar o abuso da propriedade privada como principal causa dos problemas sociais e econômicos predominantes da época (...). Mas More foi o único a levar esse raciocínio a sua conclusão integralmente platônica (...)". ${ }^{13}$ De acordo com More, os utopianos já adotaram essa solução, e dessa forma aboliram as hierarquias sociais e estabeleceram uma república virtuosa e harmônica.

Mas é aqui que as ideias devem ser relativizadas. Sem dúvida, More representou uma singularidade com suas conclusões acerca da supressão da propriedade e do dinheiro. Entretanto, já se observou que a Ilha de Utopia apresenta um traço que depõe contra sua perfeição: a aspiração por outra

I3 Quentin Skinner. As fundações do pensamento político moderno. Trad. Laura Teixeira Motta e Renato Janine Ribeiro. São Paulo: Companhia das Letras, I996, p. 279. 
existência pós-morte. Mas outros elementos servem a uma limitação desse ideal de república. A começar pela guerra, que apesar de malvista pelos utopianos, é praticada. Hitlodeu fala em exercícios militares, em confecção de armas, em táticas de emboscada e retirada, em estratégias de combate etc. Evidencia-se, com isso, uma espécie de arte militar e mesmo uma economia da guerra, se se considera a acumulação de dividendos visando uma guerra futura. A própria ideia de guerra futura coloca a guerra num campo de possibilidades, como algo passível de ocorrer. Pode-se afirmar que se trata de uma guerra defensiva, muitas vezes evitada e praticada como último recurso, mas não se pode negar que a guerra, mesmo execrada, redunda em benefícios para Utopia, como lucros monetários e territórios.

Outro ponto que merece uma avaliação é a inexistência de hierarquias e a igualdade e liberdade que caracterizam a Utopia. Ao relatar o regime de trabalho dos utopianos, Hitlodeu lembra que poucos estão isentos por lei do trabalho (uma vez que todos estão, por lei, obrigados a uma carga diária de trabalho): alguns magistrados e jovens destinados às ciências e às artes; tais magistrados e jovens constituem a classe dos letrados, que se opõe (enquanto atividade) à classe dos operários. Nota-se, aqui, uma contradição: a despeito da igualdade, opõe-se duas classes a partir de suas atividades; e só da classe dos letrados se escolhem os embaixadores, os padres, os magistrados e os príncipes, enquanto que o restante da população exerce profissões úteis. Temos, aparentemente, a reprodução de uma desigualdade social. Ademais, há a possibilidade de uma ascensão social. More, por meio de Hitlodeu, afirma: "Se um desses eleitos [os que se dedicam às ciências e às artes] ilude a esperança pública, é transferido para a classe dos operários. Se, ao contrário, e o caso é frequente, um operário consegue adquirir uma instrução suficiente consagrando suas horas de lazer aos estudos intelectuais, fica isento do trabalho mecânico e sobe à classe dos

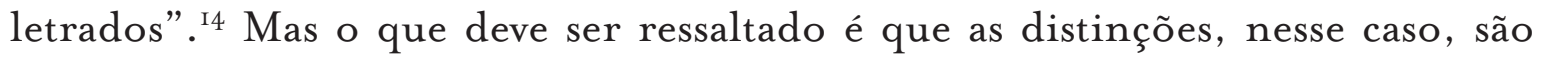
admitidas, na medida em que decorrem do mérito, não do poder econômico ou de uma preeminência nobiliárquica. Outro ponto é a questão da existência de escravos. Segundo Hitlodeu, a escravidão configura-se como uma pena ordinária para vários delitos, além de ser uma punição mais vantajosa para o Estado do que a morte. Mas isso contraria totalmente a ideia da Utopia como o lugar da ausência de hierarquias e gradações sociais. Assim, temos outra divisão, agora conforme o estatuto jurídico. Mas também convém lembrar que essa crítica soa anacrônica, uma vez que ela reflete um padrão moral que condena a escravidão como desumana, e que só surge a partir do século XIX, no bojo

I4 Thomas More. A Utopia. São Paulo: Abril Cultural, Coleção Os Pensadores, volume IO, I972, p. 229 . 
de uma mentalidade burguesa em plena transformação, rumo a uma sociedade industrial. No século XVI, a escravidão não se coloca como uma questão moral, não é um dilema. Para More, a escravidão não parece ser um problema, desde que os escravos sejam tratados com humanidade.

Todos esses desvios comprovam uma coisa muito curiosa sobre a obra de More. Pode-se enxergar em A Utopia um tipo de retrato em negativo da Europa: em Utopia, ao contrário da Europa, observam-se processos de votação para cargos importantes, a distribuição dos bens e riquezas, certo repúdio à guerra, a incorruptibilidade dos magistrados, uma grande virtude entre os padres, a própria impossibilidade de disputas sociais (na medida em que todos vivem em harmonia, sem conflitos políticos, sociais ou religiosos) etc. Poder-seia crer numa extrema oposição entre as duas realidades, mas o que ocorre é que, por meio desse jogo de contrastes, acaba-se reforçando uma ligação entre essas duas partes, revelando uma profunda imbricação de Thomas More com seu tempo. Essa premissa já se observa na própria caracterização do narrador, quando Pedro Gil, ao apresentar Rafael Hitlodeu a Thomas More, descreveo assim: "Rafael Hitlodeu conhece bastante bem o latim e domina o grego com perfeição. O estudo da filosofia, ao qual se devotou exclusivamente, fêlo cultivar a língua de Atenas de preferência à de Roma. (...) Portugal é o seu país. Jovem ainda, abandonou seu cabedal aos irmãos; e, devorado pela paixão de correr mundo, amarrou-se à pessoa e à fortuna de Américo Vespúcio. Não deixou por um só instante este grande navegador, durante as três das quatro últimas viagens (...)". ${ }^{15}$ Utiliza-se aqui dois arquétipos básicos do homem quinhentista: o navegador (e não à toa é português) e o humanista, unindo-se o conhecimento teórico ao conhecimento prático. Busca-se conferir a Hitlodeu certa autoridade, na medida em que, sendo navegador, possui conhecimento "empírico" das coisas que relata, e sendo filósofo, possui a arguição necessária para fazer juízo de suas ideias. Além disso, na medida em que More insere em sua obra o movimento de expansão do capitalismo comercial por meio das navegações, ele acaba por mencionar a América. Ivan Lins, em um pequeno livro sobre a principal obra de Thomas More, não hesita em associar a Ilha de Utopia ao Novo Mundo: "Consta ela [A Utopia] de dois livros. O primeiro é consagrado às imperfeições da humanidade antiga, e o segundo, às virtudes da que surgia. Era esta simbolizada no jovem continente americano, e aquela na velha Europa". ${ }^{16}$ Apesar de parecer mais acertado ver na Ilha de Utopia, um projeto de Europa livre da corrupção, é provável que o surgimento de um Novo Mundo tenha servido de estímulo na composição da obra.

I5 Idem, ib. p. I65.

I6 Ivan Lins. Tomás Morus e A Utopia. Rio de Janeiro: Civilização Brasileira, I969, p. 48. 
Vários outros elementos contribuem para reforçar essa vinculação de More e sua obra com o seu tempo: More começa seu livro relatando uma reunião de diplomatas, para tratar de uma querela envolvendo Inglaterra e Espanha, o que fornece um pano de fundo para a narração, inserindo-a num contexto de disputa entre os Estados europeus pela hegemonia do continente; essa reunião se dá em Antuérpia, naquele momento um dos grandes centros de distribuição de produtos da economia-mundo europeia (tomando de empréstimo a expressão braudeliana); em dado momento da narrativa, no livro I, More (por intermédio de Hitlodeu) realiza uma impressionante exposição da política externa francesa, enfatizando as políticas de alianças, as propostas de intervenção bélica visando anexações etc.; ao tratar da expulsão dos camponeses por meio da criação de pastos para os carneiros, More está criticando a política de cercamentos que se realizou na Inglaterra; descrevendo um corpo "eclesiástico" utopiano pouco numeroso, venerado por sua virtude, escolhido por votação, cujo poder se limita a velar pelas coisas divinas, pela religião e pelos costumes (portanto, destituídos de poderes temporais), More critica o corpo eclesiástico europeu corrompido, mais afeito a privilégios e desejoso de participação no poder político; ao colocar o ateísmo como algo inadmissível em Utopia, More reflete seu tempo, profundamente marcado por disputas religiosas, onde não era possível não tomar partido. Desse modo, não deixa de ser coerente afirmar que More realiza uma forma de crônica de seu tempo.

Mas é principalmente nas contradições de More, expostas acima, que se enxergam os pontos de contato do autor com sua realidade histórica, a qual invade, por meio de brechas, a sua narrativa. Ao afirmar que os utopianos faziam a guerra, a despeito de sua ojeriza, More não escapa de um ethos guerreiro e competitivo que caracteriza a Europa do século XVI; verificando-se a persistência de diferenças sociais em Utopia (representadas pela escravidão e pelos grupos de "operários" e de letrados), More, talvez inconscientemente, reafirma uma sociedade europeia estamental e desigual, apesar de criticar firmemente essa configuração social.

Por fim, a par dessa estreita vinculação de More com sua realidade, e de seu comprometimento com as premissas teóricas do humanismo do Norte, é possível vislumbrar reminiscências de um modo de pensamento medieval. Dois pontos permitem fazer essa afirmação: em primeiro lugar, Rafael, em sua narrativa, defende a figura do príncipe como elemento que garantiria a paz, a riqueza, a felicidade e a prosperidade a seus súditos, como "um pastor fiel" que "deve dedicar-se a seu rebanho, e conduzi-lo às pastagens mais férteis." ${ }^{17}$ Assim, o príncipe exerceria uma função quase sacerdotal, o que se aproxima

I7 Thomas More. A Utopia. São Paulo: Abril Cultural, Coleção Os Pensadores, volume IO, I972, p. I97. 
da concepção do soberano como sacerdote secular, presente na Alta Idade Média (cuja expressão máxima foi Carlos Magno). Em segundo lugar, a própria configuração da Ilha de Utopia como uma ilha dos afortunados, ou um paraíso na terra, condiz muito com sistemas mentais do período medieval, e se assemelha com o mito medieval do Reino de Preste João.

Ao fim da narrativa, Thomas More deixa claro que não concorda com muitas das coisas ditas por Rafael Hitlodeu, principalmente no que diz respeito à vida comunal e à ausência de dinheiro. Contudo, ele deseja ver estabelecidas na Europa muitas das leis e ideias utopianas. Skinner, a esse respeito, afirma: "a questão que aqui surge é se de nós se pretende que simpatizemos com a figura de More quando ela discorda de Hitlodeu, ou com Hitlodeu quando louva sem restrições o modo utopiano de vida, ou, ainda, que consideremos que a discussão por eles travada não pode ter nenhuma resolução clara e nítida". ${ }^{8}$ Mas essa oposição entre More e Hitlodeu é apenas aparente, podendo ser vista como um subterfúgio para expressar suas opiniões sem recear qualquer censura. Efetivamente, More se coloca amplamente a favor do fim da propriedade e do dinheiro (conforme já foi mencionado), e Hitlodeu agiria como seu alter ego. O que está em jogo é a possibilidade dessa resolução. Thomas More, tendo em consideração a imersão de sua obra nas questões de seu tempo presente e também as permanências de certas concepções pretéritas, mostra-se cético e até mesmo amargurado com relação a essa possibilidade, colocando-a mais como aspiração do que como esperança.

\section{Referências bibliográficas.}

ARISTÓTELES - A Política. Trad. Roberto Leal Ferreira. São Paulo: Martins Fontes, I998.

BARON, Hans - En busca del humanismo cívico florentino. Ensayos sobre el cambio del pensamiento medieval al moderno. Trad. Miguel Abelardo Camacho Ocampo. México: Fondo de Cultura Econômica, I993.

KRISTELLER, Paul - Tradição clássica e pensamento do Renascimento. Trad. Artur Morão. Lisboa: Edições 70, I995.

I8 Quentin Skinner. As fundações do pensamento político moderno. Trad. Laura Teixeira Motta e Renato Janine Ribeiro. São Paulo: Companhia das Letras, I996, p. 275. 
LINS, Ivan - Tomás Morus e A Utopia. Rio de Janeiro: Givilização Brasileira, I969.

MORE, Thomas - A Utopia. São Paulo: Abril Cultural, Coleção Os Pensadores, volume IO, I972.

SKINNER, Quentin - As fundações do pensamento político moderno. Trad. Laura Teixeira Motta e Renato Janine Ribeiro. São Paulo: Companhia das Letras, I996.

"Sir Thomas More's Utopia and the language of Renaissance humanism". In: PAGDEN, Anthony (org.) - The Languages of political theory in earlymodern Europe. Cambridge [Cambridgeshire]; New York : Cambridge University Press, Série Ideas in Context, I987.

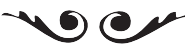

Adriano Saturnino dos Santos é graduando em História pela USP.

E-mail: adriano_sasan@yahoo.com.br 